\title{
Comprehensive analysis of internal and surface defects of ceramics
}

\author{
Sergey N. Grigoriev ${ }^{1}$ and Marina A. Volosova ${ }^{1}$ \\ ${ }^{1}$ Moscow State University of Technology "STANKIN",1 Vadkovskiy per., Moscow, 127055, Russia Federation
}

\begin{abstract}
System approach to studying of causes of infringement of operational characteristics tool ceramic materials on the basis of complex researches and systematization of their volume and superficial defects is presented in article. The main directions of improvement of tool ceramics are allocated
\end{abstract}

Keywords: ceramics, cutting tool, fragile destruction, diamond processing, durability, structural defects, coatings.

\section{Introduction}

The research conducted in the field of studying of the causes of destruction of tool ceramics, show that the main cause of operability loss of ceramics in the process of operation is brittle fracture. The failures caused by brittle fracture account up to $55 \%$ of all failures of ceramics when turning and up to $80 \%$ when milling.

The reason for this are the low strength properties and responsivity of ceramics to cyclic loads and thermal shocks, which are the result of volume and superficial defects in the structure of ceramics, formed at different stages of its life cycle.

\section{Structural features of tool ceramics}

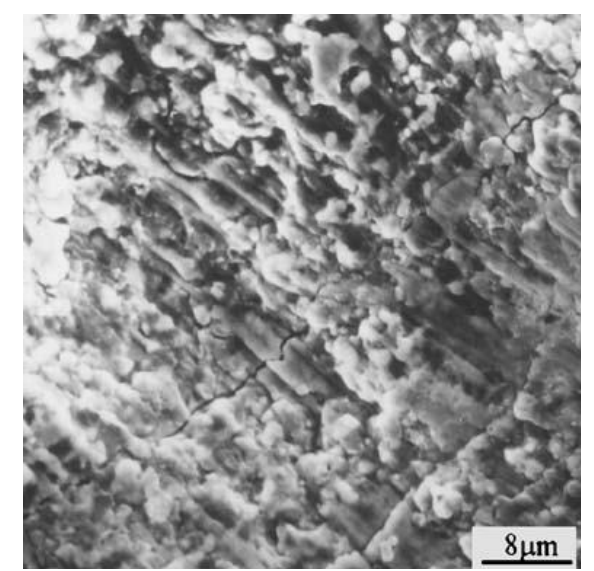

Figure 1: Formation of cracks on the face of tip.

Applying Griffiths failure theory on ceramic tool materials, taking into account the availability in their volume of a granular structure and structural heterogeneity, we can conclude that in the volume and on the surface of the cutting plate there are always conditions of formation and development of cracks. Physical objects for formation of cracks are the interfaces of the grains and inclusions of another chemical composition (Fig. 1). These boundary surfaces are stress concentrators and the source groups of points, from which begins the origin and development of cracks in the volume of the ceramic die (Fig. 2).

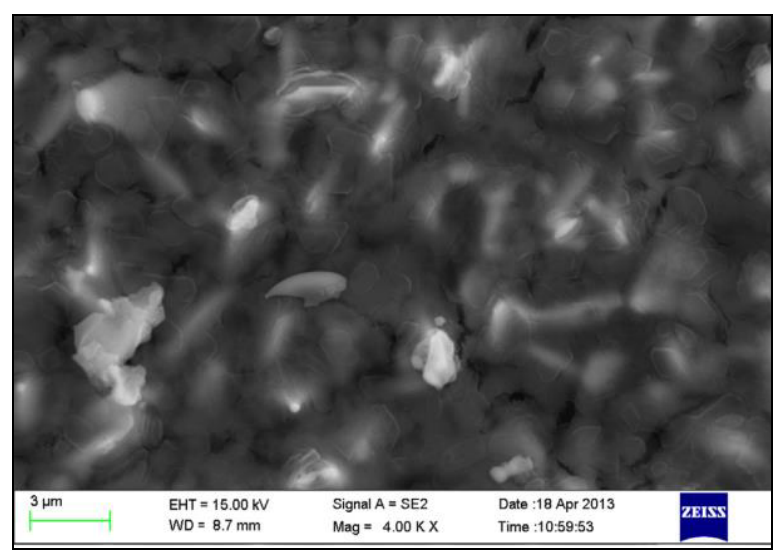

Figure 2: SEM micrograph of structural heterogeneity of tool ceramics.

Taking into account granular structure and structural heterogeneity of ceramics it is reasonable to make the assumption that the weakest points of the ceramic die are the interfaces between ceramic grains and between the grains and inclusions of different chemical composition [1]. At the interface between the grains is formed the front of inner stresses, concentrate the vacancies, arise nonequilibrium thermodynamic potentials. In the unloaded ceramics these forces are balanced in the volume of ceramic die with interatomic interaction forces. The grains in the ceramic die are arranged randomly and contact each other under 
developed and arbitrarily located in space surfaces. Therefore, in the same way at the grain boundaries will be aligned the microcracks in the ceramic die.

\section{Defects of tool ceramics arising in the process of production}

The reduce of porosity is an important issue of technology of manufacturing of ceramics, because the pores are the concentrators of stress and vacancies. (Fig. 3). Properties of ceramics are determined by the overall porosity and its type (closed and opened).

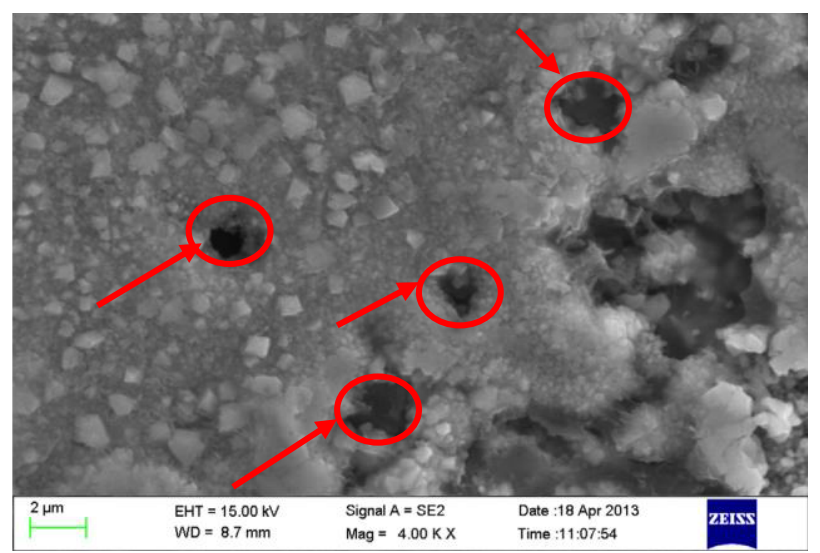

Figure 3: SEM-microphotography of the voids on the surface of the tool ceramic.

By origin it is possible to classify the following types of pores: technological pores formed during pressing: interparticle, intraparticulate, layering pores;

technological pores formed during heat treatment: shrinkage and thermal; secondary, diffusion, coalescence, dislocation, capillary pores.

Intragranular porosity and intergranular porosity are finally formed in the ceramic die as a result of sintering [2]. During the sintering of the ceramic material take place several physico-chemical processes and the sintered product gets certain properties. Thus there is thickening and hardening of the ceramic due to the transfer and redistribution of the material.

The concept of structural heterogeneity for tool ceramics (Fig. 4) is a fundamental physical property and has a wider meaning than for conventional metals and alloys. Under structural heterogeneity of tool ceramics should be understood not only the presence of inclusions of different chemical composition with boundaries in the material volume, but also the presence of structural defects of different types : pores, cracks, cuts, sinks, etc. in the volume of material and on the surface of tool plates.

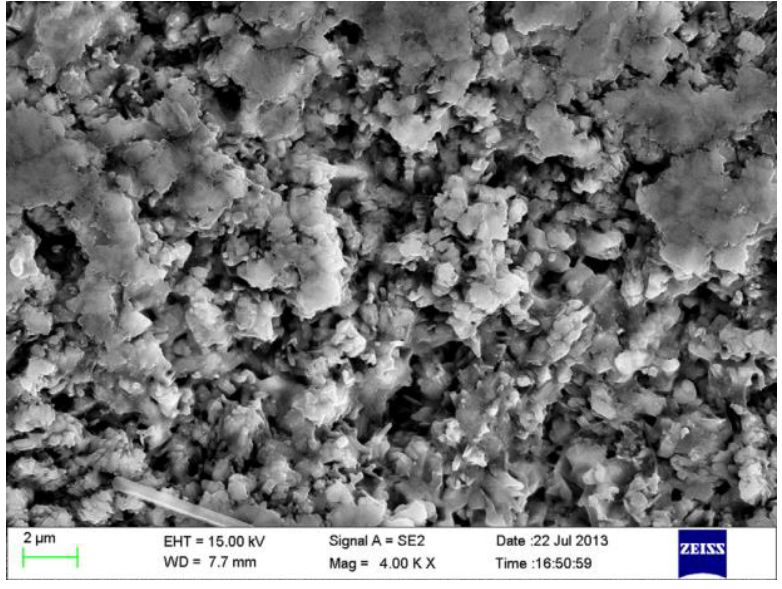

Figure 4: SEM-microphotography of the structural imperfection of the tool ceramic.

\section{Defects of tool ceramics arising in the process of finishing treatment}

The most effective method of final machining of tool ceramics are diamond grinding and lapping. The processes that occur during stock removal in diamond grinding, have a significant impact on the operational characteristics of the cutting plate. (Fig. 5). The defining role of defects in the formation of the mechanical properties of ceramics is generally accepted [3].
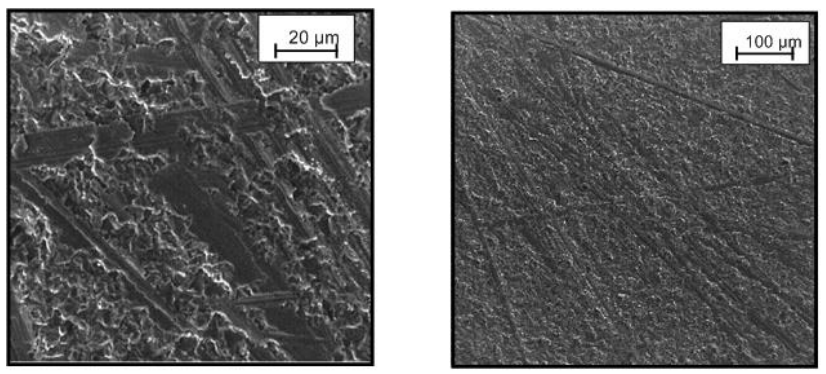

Figure 5: Typical view of the surface of oxide-carbide ceramics after diamond grinding.

In the favorable modes of grinding ceramic plate is not in contact with a post of diamond grinding wheel and the cutting grain is embedded into the material by 0.2-0.4 of the protruding part. The analysis of the process of finishing of the tool ceramics allows to note the following important features.

a) Not all of the grains of the ceramic material will escape from the machined surface of the plate, but only those that protrude above the surface on more than $0,5 W_{l}$. Here $W_{l}$ is the average grain size of the ceramic material.

b) After the tearing out of grain of ceramic material at the place of its location will be formed a crater, having the size and shape of the inverse-depth parts of the grain in Table 1. As the size of the in-depth part of the grain in our model is always less then the size of the protruding one, as the result of grinding the roughness 
of the machined surface will decrease. The depth of the single crater is always less than half of the nominal size of the ceramic grain.

c) The number of torn grains of ceramic material and the number of craters on the treated surface depend on the homogeneity of the structure and granularity of tool ceramics.

Another characteristic defect of finishing are the so-called grinding microcracks. Practice shows that microcracks form on the surface of ceramics even in the soft modes of grinding, and it reduces the level of its mechanical strength. The destruction of the machined ceramics is usually initiated by a critical surface defect (the weakest link). Another typical defect are marks of the grinding wheel (grinding scratches) (Fig. 6) remaining on the surface of the cutting plate after finishing treatment. The negative effect of grinding scratches on the properties of the ceramics is that traces of the grinding wheel, being in size, in particular, in depth, much bigger than the grains of ceramics, create on the surface of the plate the estimated sources and trajectories for the formation and development of crack front during operation of tool ceramics.

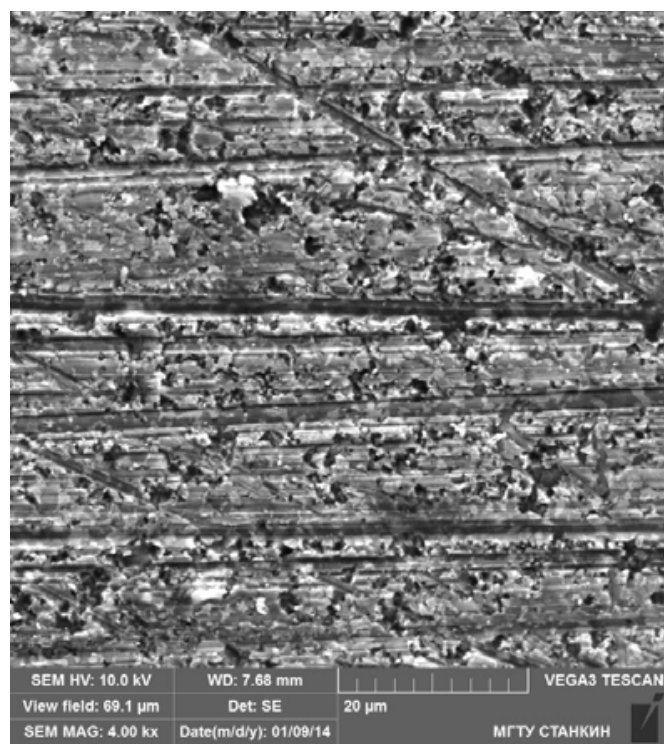

Figure 6: SEM-microphotography of the grinding wheel marks on the face of tip from the mixed CC650 ceramic.

\section{Defects of the tool ceramics arising in the process of operation}

The study of the tool ceramics from the point of view of structurally inhomogeneous material allows to notice that even in the initial state ceramics contains microcracks, which are localized at the grain boundaries of the material. The grains in the ceramic die are arranged randomly and are in contact with each other under developed and arbitrarily located in space surfaces. Similarly, in an arbitrary order along the grain boundaries appear microcracks in the ceramic die. Under cyclic loading conditions and the intermittent nature of the cut (for example, when milling) on the surface of the cutting plates appear cracks (in the literature these cracks often called planar fractures), resulting in a failure of ceramics in the form of brittle fracture [1]. A sufficiently reasonable assumption that can be made is that these cracks are a development of existing microcracks, which are located at the grain boundaries.

Another typical defect of ceramics, manifested in the course of operation is thermal cracking. The cutting process is accompanied by severe plastic deformation of the processed material and friction at the contact surfaces of the tool, resulting in a large amount of developed heat. Ceramic tools are used typically at high speeds, leading to the appearance of high local temperatures on the front and back surfaces of the tool. Thermophysical properties of ceramic tool (heat capacity, thermal conductivity and thermal expansion) determine the conditions of the thermal load of the cutting edge associated with the balance of heat flows into the cutting tool, chips and processed material, as well as the ability of the cutting tool to resist thermal stresses without failure.

\section{Systematization of the defects of tool ceramics}

Using the analysis of works of reputable scientists, as well as studies conducted in MSTU "STANKIN", of systematization of surface and volume defects of tool ceramics was based on the technological principle of formation of a defect at a certain stage of the life cycle in manufacturing (press molding and sintering), finishing (diamond grinding and polishing) and operation in Table 1.

Table 1. Systematization of surface and volume defects of the tool ceramics.

\begin{tabular}{|c|c|}
\hline Processes & Type of defect \\
\hline $\begin{array}{l}\text { Production } \\
\text { of ceramics }\end{array}$ & $\begin{array}{l}\text {-Extraneous inclusions } \\
\text {-Conglomerates of structural components } \\
\text {-Structural heterogeneity } \\
\text {-Intergranular porosity } \\
\text {-Intraganular porosity }\end{array}$ \\
\hline $\begin{array}{l}\text { Finishing } \\
\text { of ceramics }\end{array}$ & $\begin{array}{l}\text {-Torn out grains } \\
\text {-Grinding cracks } \\
\text {-Burn marks } \\
\text {-Marks of the grinding wheel } \\
\text {-Residual abrasive }\end{array}$ \\
\hline $\begin{array}{c}\text { Operation } \\
\text { of ceramics }\end{array}$ & $\begin{array}{l}\text {-Impact loading cracks } \\
\text {-Thermal cracks } \\
\text {-Abrasive wear } \\
\text {-Adhesive wear } \\
\text {-Chemical corrosion }\end{array}$ \\
\hline
\end{tabular}

For example, among the defects arising in the process of pressing and sintering of ceramics are intragranular porosity, intergranular porosity, structural heterogeneity, conglomerates of structural components, inclusions and contaminants. Characteristic defects of finishing of tool ceramics are torn out grains, grinding cracks, marks of the grinding wheel, burns and residual abrasive material in the 
microroughnesses. Typical defects arising during operation processes of the cutting tool, are impact loadings and thermal cracking, abrasive and adhesive wear and chemical corrosion.

\section{Conclusion}

The study provides an opportunity to create a system of scientific views on the problems of improving and expanding of the field of application of the ceramic tools. All areas of development and improvement of tool ceramics are associated with the improvement of its mechanical properties, mainly due to minimization of defects formed at different stages of its life cycle.

Most of these defects are formed in the surface layer of ceramics in manufacturing and operation. This fact demonstrates the need for the development and application of technological methods of targeted exposure on the surface layer of the ceramics by coating and/or modification of tool ceramics, which is used after its sintering and shaping, i.e. operations in which appear technological defects.

The work is performed with financial support of the Russian Science Foundation within the Agreement No. 14-29-00297 of August 6, 2014.
The work is carried out on the equipment of the Center of collective use of MSTU "STANKIN" with financial support of the Ministry of Education and Science of Russian Federation, the Agreement No. 14.593.21.0004 of 04.12.2014, the unique identifier of the project RFMEFI59314X0004.

\section{References}

1. N.Y. Cherkasova, M.A. Volosova Improving of the Performance of Ceramic Cutting Plates by Mechanical and Ion-Plasma Surface Treatment. Russian Engineering Research. V. 33. 7 (2013), 429-432.

2. V.V. Kuzin, S.N. Grigoriev, M.A. Volosova Effect of a tic coating on the stress-strain state of a plate of a high-density nitride ceramic under nonsteady thermoelastic conditions. Refractories and Industrial Ceramics. V. 54.5 (2014), 376-380.

3. V.V. Kuzin, M.A Volosova, M.Y. Fedorov Wear of tools from nitride ceramics when machining nickel-based alloys. Journal of Friction and Wear. V. 34. 3. (2013), 199-203. 